\title{
HORMONAL REQUIREMENTS FOR THE UTERINE ATTACHMENT REACTION AND BLASTOCYST IMPLANTATION IN THE MOUSE, HAMSTER AND GUINEA-PIG
}

\author{
K. HEDLUND AND O. NILSSON \\ Institute of Human Anatomy, S 752 20, Uppsala, Sweden
}

(Received 13th January 1971)

Before implantation occurs, a lumen containing secretion can be demonstrated in the uterus of the rat, mouse, hamster and guinea-pig. This luminal space disappears when implantation occurs, the apposing luminal surfaces of the mucosa coming into close contact. This phenomenon has been named the 'attachment reaction' of the uterine epithelium (Nilsson, 1970).

In the rat, the preimplantation appearance of the uterine mucosa can be maintained, by giving progesterone during experimentally delayed implantation (Nilsson, 1966) or by giving progesterone to spayed rats (Ljungkvist, unpublished). Implantation and the attachment reaction do not take place until oestrogen is given (Mayer \& Nilsson, 1966). In the hamster, implantation occurs without the addition of oestrogen when progesterone is given to animals ovariectomized early in pregnancy (Prasad, Orsini \& Meyer, 1960; Harper, Dowd \& Elliott, 1969) and in the guinea-pig, even progesterone is not necessary (Deanesly, 1960). Although, in the mouse, the blastocysts of an experimentally delayed implantation do not implant until oestrogen is given (Humphrey, 1967), progesterone injected into spayed, unprimed animals is capable of inducing the attachment reaction (Martin, Finn \& Carter, 1970).

This implies that the uterine epithelium of these animals reacts differently to injections of progesterone. To test the effect of progesterone on the uterine attachment reaction, spayed mice, hamsters and guinea-pigs were given progesterone for varying times, and the effects on their uterine luminal membranes were examined under the electron microscope.

Each group of species consisted of spayed animals in four subgroups, with three animals per subgroup. The animals were prepared for fixation of their tissues 15 to 20 days after ovariectomy and subsequent progesterone treatment for $0,4,6$ or 8 days, respectively. The mice and hamsters were given $2.5 \mathrm{mg}$ progesterone (AB Leo, Helsingborg) daily and the guinea-pigs $4 \mathrm{mg} / \mathrm{day}$. The fixation was effected by an aortic perfusion of $2.5 \%$ glutaraldehyde in Soerensen's phosphate buffer, $\mathrm{pH} 7 \cdot 2$, or, in the case of guinea-pigs, by an immersionfixation in situ of the uterine horns, using picric acid-formalin (Zamboni \& De Martino, 1967) as fixative. Postfixation was performed in a buffered solution of osmium tetroxide; the specimens were embedded in Epon and sectioned for light and electron microscopy. 
The results showed that an attachment of apposing luminal surfaces was present in the spayed mouse and hamster after a 4-day treatment with progesterone and in the spayed guinea-pig after a 6-day treatment. In the rat, however, closure of the uterine lumen does not follow upon the administration of progesterone (Ljungkvist, unpublished). Thus, in some rodents, the uterine attachment reaction is induced by progesterone, while in others both progesterone and oestrogen are necessary.

The first stage in implantation, blastocyst attachment, begins with surface contact between trophoblast and uterine luminal epithelium in both the rat and the mouse (Mayer \& Nilsson, 1966; Reinius, 1967). Since implantation in the mouse fails to occur although epithelial apposition has taken place, the block to implantation may depend upon a lack of close contact between trophoblast and uterine epithelium.

This problem was studied by examining the epithelial-epithelial and epithelial-trophoblast boundaries in pregnant spayed mice, maintained in a state of experimentally delayed implantation by progesterone. Four CBA mice were ovariectomized 2 days after mating and given $2.5 \mathrm{mg}$ progesterone for 6 days. The animals' tissues were then fixed by perfusion, and two to three uterine sites with blastocysts from each animal were sectioned for electron microscopy.

The results showed that the uterine lumen was generally closed (Pl. 1, Fig. 1). Under the light microscope, the trophoblast seemed to be attaching to the uterine epithelium at the blastocyst sites (Pl. 1, Fig. 2). Electron microscopy, however, showed that the trophoblast surface membrane was resting on top of irregular microvilli and ran parallel with the uterine luminal epithelium in only a few areas (Pl. 1, Fig. 3). Thus, one reason for the failure of implantation could be that the cell membrane of the trophoblast does not come into sufficiently close contact with the uterine luminal surface. Since the uterine epithelium seems to have the capacity to form close contacts, it is possible that some properties of the cell membrane of the trophoblast are responsible for making implantation impossible. This issue is now under study.

To conclude, progesterone alone causes an epithelial attachment in the uterus of the mouse, hamster and guinea-pig but not in that of the rat. Although the uterine attachment reaction is present in the mouse during experimentally delayed implantation, the cell membrane of the trophoblast is separated from that of the uterine epithelium. It is assumed that the properties of the trophoblast cell membrane make a blastocyst attachment impossible.

\section{EXPLANATION OF PLATE 1}

FIG. 1. Mouse uterine epithelium during experimentally delayed implantation, being treated with progesterone for 6 days. The basal part of the epithelium contains many lipid granules and its surface forms a close contact with apposing epithelial cells. $\times 281$. FIG. 2. Blastocyst in the uterine lumen of a mouse in a state of experimentally delayed implantation, being treated with progesterone for 6 days. The uterine epithelium tightly surrounds the blastocyst. $\times 281$.

Frg. 3. Trophoblast and uterine epithelium of a mouse in a state of experimentally delayed implantation, being treated with progesterone for 6 days. The arrows point to the trophoblast-epithelial junction. The trophoblast rests on irregular projections of the epithelial cells, and in between the projections there are narrow spaces which separate the blastocyst from the uterine epithelium. $\times 18,100$. 

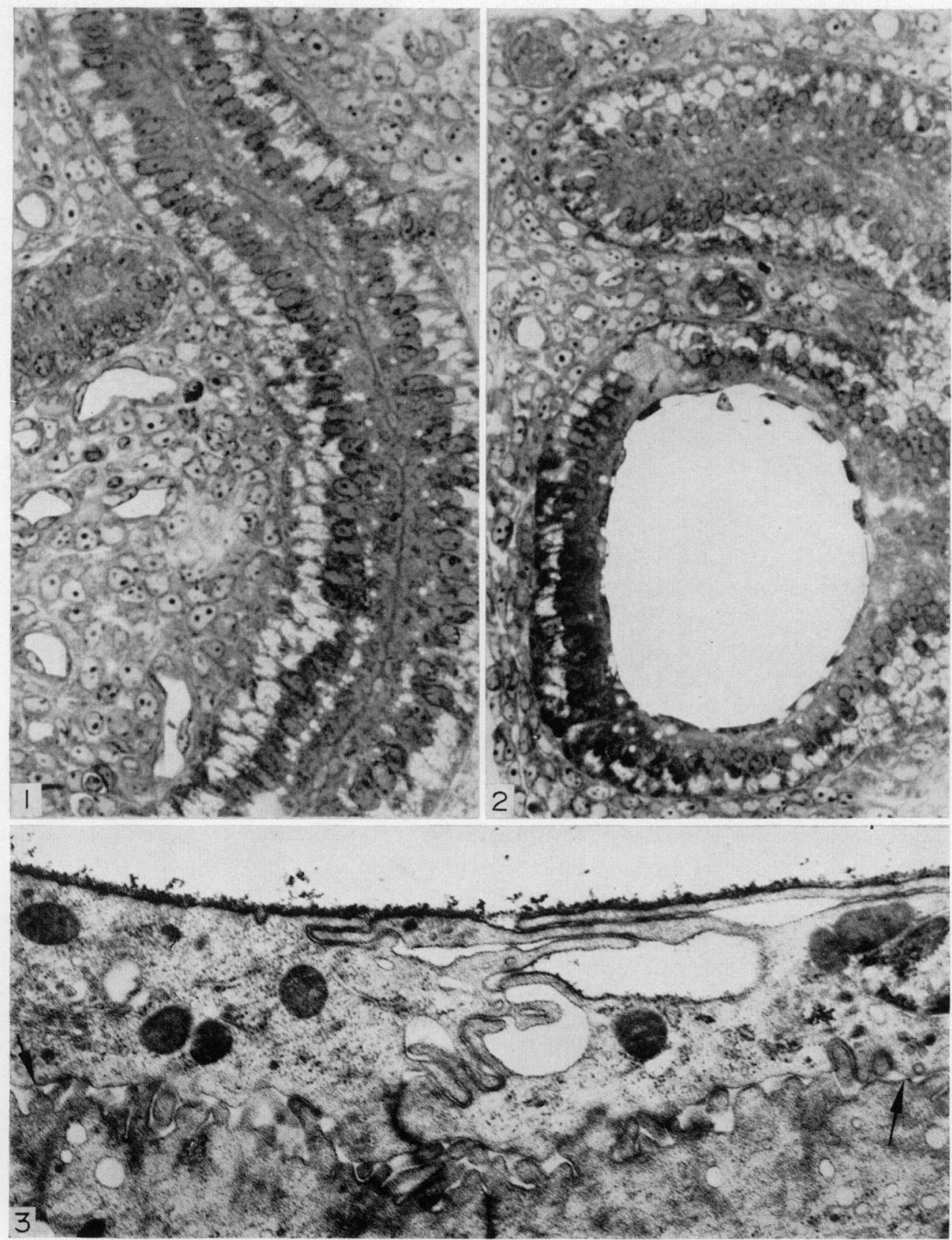
The Swedish Medical Research Gouncil (Project Nr B71-12X-70) contributed to the costs of this investigation.

\section{REFERENCES}

DeANEsLy, R. (1960) Implantation and early pregnancy in ovariectomized guinea-pigs. 7. Reprod. Fert. 1, 242.

Harper, M. J. K., Dowd, D. \& ElliotT, A. S. W. (1969) Implantation and embryonic development in the ovariectomized-adrenalectomized hamster. Biol. Reprod. 1, 253.

Humphrey, K. W. (1967) The induction of implantation in the mouse after ovariectomy. Steroids, 10, 591.

Martin, L., Finn, C. A. \& Garter, J. (1970) Effects of progesterone and oestradiol-17 $\beta$ on the luminal epithelium of the mouse uterus. 7. Reprod. Fert. 21, 461.

Mayer, G. \& Nilsson, O. (1966) Normal and retarded nidation in the rat: an ultrastructural study of the uterine epithelium and of the blastocyst. Proc. Vth Congr. Fert. Steril., Excerpta Med. Int. Congr. Ser. No. 133.

Nilsson, O. (1966) Structural differentiation of luminal membrane in rat uterus during normal and experimental implantations. Z. Anat. EntwGesch. 125, 152.

Nilsson, O. (1970) Some ultrastructural aspects of ovo-implantation. In: Ovo-Implantation. Human Gonadotropins and Prolactin, p. 52. Ed. P. O. Hubinont et al. Karger, Basel.

PRASAD, M. R. N., ORsini, M. W. \& MEYeR, R. K. (1960) Nidation in progesterone-treated estrogendeficient hamsters, Mesocricetus auratus (Waterhouse). Proc. Soc. exp. Biol. Med. 104, 48.

ReINius, S. (1967) Ultrastructure of blastocyst attachment in the mouse. Z. Zellforsch. mikrosk. Anat. 77, 257.

Zamboni, L. \& DE MARtino, C. (1967) Buffered picric acid-formaldehyde: a new, rapid fixative for electron microscopy. F. Cell Biol. 35, 148A. 